\title{
THE DEGREE OF COMMUNITY ENGAGEMENT: EMPIRICAL RESEARCH IN BALTIMORE CITY
}

\author{
Soyoung PARK ${ }^{1)}$, Sungchan KIM $^{2)}$ \\ 1) University of Baltimore, USA, ${ }^{2)}$ Mississippi State University, USA
}

\begin{abstract}
The purpose of this study is to investigate influential factors that affect the levels of community engagement. Factors include community-level characteristics as well as demographic features of individuals in the community of Baltimore City. The study examines various community factors that affect the level of community engagement in the urban area, such as the level of homeownership, socioeconomic factors such as income and education, and demographic factors such as race, age, and sex. Findings from the study indicate that various factors from the social-cum-ethnic stratification influence the degree of community engagement in this urban area. Specifically, communities with high income levels and high levels of homeownership are more likely to induce residents to participate in their community. With regard to demographic factors, African-Americans and persons over the age of 65 years old are more willing to engage in community activities.
\end{abstract}

Key Words: community engagement, social-cum-ethnic stratification, urban community.

\section{Introduction}

Recently, community engagement has gained favor as a tool for solving community problems. Although the term 'community engagement' is defined in various ways, according to the CDC (1997), community engagement is defined as "the process of working collaboratively with and through groups of people affiliated by geographic proximity, special interest, or similar situations to address issues affecting the well-being of those people" (CDC 1997: 2). This definition implies that the attributes of citizen participation can influence the systems and uses of the resources of a community. This leads to environmental and behavioral changes in the community through the changing policies and practices of participation (Fawcett et al. 1995). For example, communities with higher levels of engagement easily attain better performance (i.e., lower crime rates) for governmental institutions.

Community engagement is also explained by the culture of a community (Blumenthal and DiClemente 2004, Malow et al. 2005, Silka et al. 2008). Studies on cultural influences argue that individual behaviors are directly affected by the culture of each community. As a result, several elements and rules of community culture may serve as potential tools for improvement in community conditions or individual behaviors. This is because culture is related to "the integrated pattern of human knowledge, belief, behavior, and material traits characteristic of a social group" (Braithwaite et al. 1994: 409). In addition, some scholars explain the local political engagement based on the social-cum-ethnic stratification in urban politics (Cox 2011). That is, the jurisdictional fragmentation of communities in a specific region has a different disposition in terms of engagement because of the social-cum-ethnic stratification.

Thus, a number of factors in a community's culture and social structure can influence the degree of community engagement. For example, a community with a high level of 
homeownership might demonstrate a more viable community engagement. This is because homeowners are more willing to invest their time and resources in the community, and they are also more likely to settle down and establish a foundation. Additionally, communities with more minorities may be less likely to expect their residents to engage in the community, because it is difficult to comprehensively include all people of diverse racial or ethnic backgrounds.

The purpose of this study is to investigate the causes of differences in community engagement in the metropolitan area of Baltimore City. Specifically, this research attempts to identify which factors in a given urban community lead to differing degrees of community engagement. This includes socioeconomic factors in the community, as well as the composition of residents. The paper examines various 'community factors,' which people attain through socialization rather than merely as a result of biological factors. They include the level of homeownership and other socioeconomic factors, such as income and educational level. Further, this study attempts to determine which factors, from the social factors of the community to individual characteristics, are more influential in explaining the differences in the degree of community engagement in urban areas.

The majority of the existing research explains this phenomenon by using only 'traditional factors' of individuals in the community, such as race, gender, and age. Additionally, the extant research focuses primarily on the effectiveness of community engagement on a community's conditions. However, in our analysis, we attempt to identify more comprehensive factors that lead to differences in the community engagement level. In order to capture "community" more clearly, this study is also conducted empirically with the unit of the neighborhood level in a metropolitan area. Community engagement activities have been studied at a micro-level, such as neighborhoods in the urban area. As a result, this study may provide evidence as to why community engagement has a different pattern in each community and it anticipates some findings so that practitioners can better understand the socioeconomic dynamics of community engagement in metropolitan areas.

\section{Materials and Methods}

\section{Meaning of Community Engagement}

As society has become more democratized and decentralized, citizens have become more willing to participate in government work and they have expressed greater interest in improving the social conditions in their own jurisdiction. Such a trend change begins with the changes of the individual roles in a given society. The extent of the change is characterized as a move toward collective action. Civic engagement through collective action is a value choice, and the action of value choice is implemented by individual participation in the community. This civic engagement is explained through the concept of social capital (Bourdieu 1986, Coleman 1988, 1990, Putnam et al. 1993). Social capital might be helpful in understanding the collective action of self-interested individuals. Thus, community engagement is explained through social capital.

According to Putnam (1993: 167), "social capital refers to features of social organization, such as trust, norms, and networks that can improve the efficiency of society by facilitating coordinated actions". There are many existing studies that use participation as a social capital indicator, such as engagement in the local community (Onyx and Bullen 2000) and political engagement. In recent history, during the process of policy-making and implementation, policy makers have created more chances for engagement from citizens and they have also induced greater participation. Additionally, "the jurisdictional fragmentation along with the serious powers and responsibilities delegated to individual municipalities" (Cox 2011: 2662) have 
provided decentralized and privatized characteristics for policy implementation in the local governments in the U.S. Thus, citizen engagement must be explained in the light of these conditions.

In terms of the meaning of community engagement, "community" is considered a somewhat vague and value-laden term. However, Head (2007: 441) characterizes it as a "euphemistic term that glosses over the social, economic and cultural differentiation of localities or peoples". In addition, "engagement" implies an active relationship with the government in policy setting. Thus, community engagement provides a new approach of covering a variety of groups, such as wide-ranging constituencies and disadvantaged groups, in the decision-making process (Head 2007). Community engagement plays an important role as a means of achieving positive consequences such as "mutual support, cooperation, trust, and institutional effectiveness" (Putnam 2000: 22). However, the level of engagement was considered to be on the decrease during the last third of the twentieth century. Recently, community engagement in urban areas has taken on a more depoliticized aspect due to privatization in the community. This implies that social-cum-ethnic stratification influences the degree of community engagement (Cox 2011).

Previous literature makes an effort to form institutional bridges between governments and citizens, often termed "community engagement" (Head 2007). Specifically rooted in geographic grounds, community engagement implies the collective action of individuals in pursuit of diversified participants in the community (Queensland Department of Emergency Services 2001). Moreover, as city resources and public service provisions have become scarce in urban areas, citizens have begun to take collective action in order to solve social inequities related to deteriorating neighborhoods. In conclusion, neighborhoods, as a unit of community engagement, play an important role as a social structure in promoting community improvement.

Therefore, community engagement pursues a coalition of citizens so that they not only share information and resources, but also support particular program changes (Cohen et al. 1994). Citizen coalitions have a grassroots base in the community, and they are strongly affected by community factors such as established rules/ procedures, type of leadership, degree of engagement, and diversity of participants in the community (Kellogg Foundation 1997, Zakocs and Edwards 2006). When community engagement becomes successful, citizens also benefit from it. In the final analysis, such benefits increase overall trust and lead to improvements in the delivery of services (http://www.homesandcommunities.co.uk).

\section{The Framework for Community Engagement}

The field of social ecology is interested in the "interrelations among environmental conditions and human behavior and well-being" (Stokols 1996: 285). Specifically, analyses in socioecology describe environmental situations with multiple physical, social, and cultural dimensions that can affect the process of social coalition. Additionally, the research of socio-ecology underscores the dynamic interactions between situational and personal dimensions. Stokols (1996) argues that the social ecology model may explain why citizens make an effort to participate in community: social cohesion and well-being are influenced by the physical, social, and cultural factors of community, as well as personal features. Citizens are affected by multiple environments, such as neighborhood, geographic elements, and community structure and these factors diffuse and influence each other. Thus, community engagement has different patterns that are dependent upon heterogeneous factors. 
Traditional Factors in the Degree of Community Engagement

According to previous research, participation patterns are explained by demographic variables such as race, age, and gender. For example, older people are known to be more likely to interact with elected representatives. Additionally, rich and well-educated people are more likely to participate in voting (Keaney and Rogers 2006). Men and women tend to participate equally in traditional politics (Hansard Society 2009), and political analysts recognize that gender gaps in citizen participation have been diminished (Coxall et al. 1998). However, the gender gap in voting is still evident in some studies (Keaney and Rogers 2006).

Previous research has found that individuals recognize benefits in terms of their well-being and experience social relationships through community engagement. However, some individuals perceive unintended negative values of community engagement. For example, exhaustion and stress, as well as the time commitment and expenditure of financial resources, impede community involvement for some, because community engagement requires their physical and financial contributions (Attree et al. 2011). In summary, citizen engagement produces gains and losses, depending upon which characteristics are affected by it. In examining influential factors, most previous research has focused exclusively on demographic factors. Thus, this study attempts to demonstrate community engagement by examining different characteristics that apply to the socioecological framework: jurisdictional fragmentation of homeownership, median income in each community, and educational level, in addition to other traditional factors (Fig. 1).

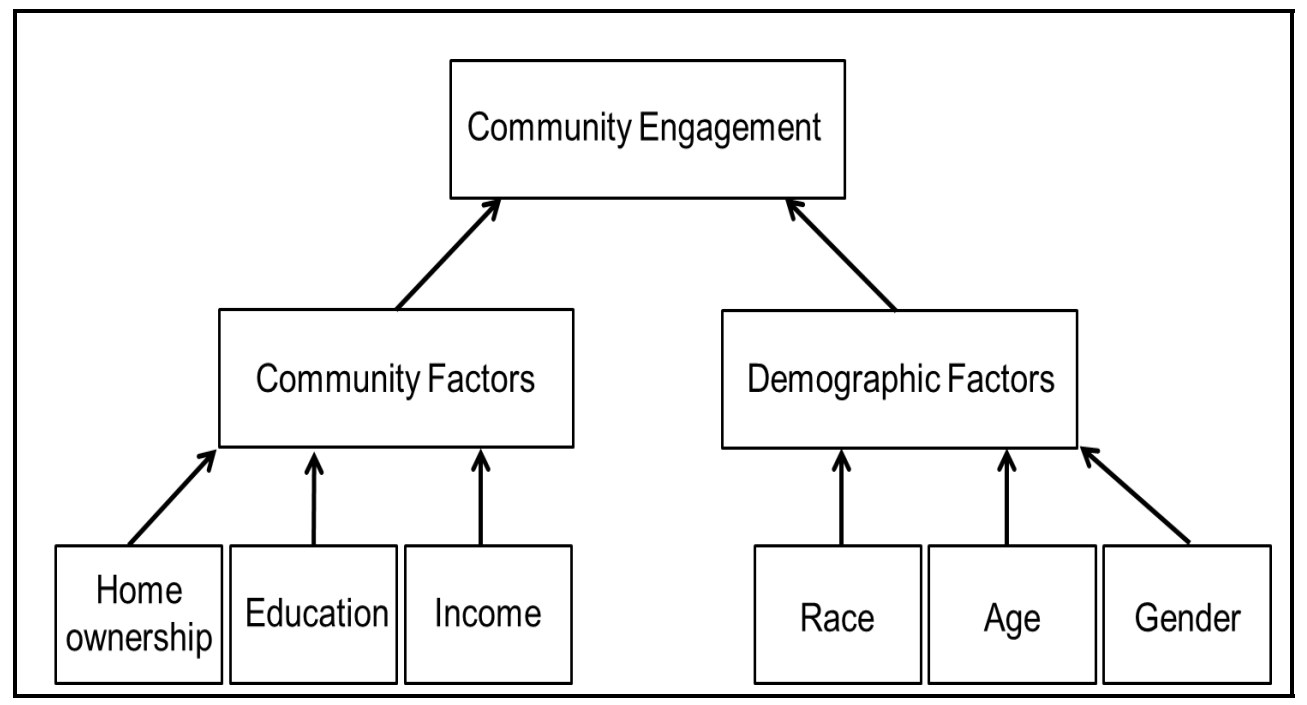

Fig. 1 - Conceptual Framework of Community Engagement

\section{Hypotheses - Community Characteristics}

In terms of quality of life in neighborhoods, homeownership is one of the most important factors to consider. It is related to externalities, such as schools and recreation, which residents create themselves or through interaction with the local government (Cox 2011). Homeownership has positive effects on both individuals and society, such as quality of citizens, constancy of neighborhoods, and durability of communities (Rohe et al. 2002). Research has yielded 
valuable evidence regarding the positive impacts of homeownership on community engagement. Homeowners tend to: a) be more satisfied with regions; b) contribute more to the community in voluntary activities; and c) be less mobile, which contributes to the stability of a community (Rohe et al. 2002).

Previous research demonstrates that people with a high income are more likely to participate in public activities than those with a low income (Keaney and Rogers 2006, Hansard Society 2009). This is because a lack of financial resources prohibits citizens from community engagement. According to Low et al. (2007), insufficient disposable income is consistently the most prominent reason people cannot afford to donate to charities and participate in charitable activities. Additionally, financial expenses associated with an increased role in community engagement can be an obstacle to involvement (CLG 2008).

The educational level of residents in a community is considered a significant predictor of participation, because education enlightens citizens and it propels them into community engagement (Brodie et al. 2009). Musick and Wilson (2007: 120) argue: "the more education people have, the more extensive and heterogeneous are their social networks, which increases the chance they will be asked." Thus, citizens with a low level of education face challenges and difficulties in terms of participation. The Department of Communities and Local Government (CLG 2008) reveals that the educational gap can create barriers of engagement in community activities in other ways. Lack of understanding about the participation process can inhibit people with low educational levels from becoming engaged (Brodie et al. 2009).

H1: A community with a high level of homeownership has more viable community engagement. H2: A community where people have a high level of education has more viable community engagement.

H3: A community with a high income level has more viable community engagement.

\section{Hypotheses - Demographic Characteristics}

Traditionally, some researchers, such as McGregor et al. (1992), have argued that demographic characteristics are critical factors in determining the degree to which people engage in their community. Brownill and Darke (1998) find that opinions of minorities and women are not well reflected in the 'regeneration policy' process, although they are one of the primary beneficiaries. Even in political activities, their voices are rarely represented, and it has been suggested that men are more likely to be interested and engaged in political activities (Hansard Society 2009). Additionally, Burton et al. (2004) found that women are less likely to participate in community activities because women have less confidence, they are subject to economic discrimination, and they are also typically disproportionately burdened with housework. Women are also excluded from participation because of the male-focused culture of regional government (Haberis and Prendergrast 2007).

Regarding race, minority groups have been excluded in social participation because of the application of stereotypes, such as language barriers and cultural differences (Burton et al. 2004). Research has found that African-Americans and other minority groups are less likely to participate in political activities than white groups (Hansard Society 2009). Blakey et al. (2006) suggest that particular groups may face higher barriers within their own communities, and this discourages individual engagement. In particular, Rai (2008) finds that minorities and minority women often face gender and race discrimination. This means that these groups cannot viably participate in political activities. 
In terms of age, McGregor et al. (1992) argue that age influences participation in local government. According to these researchers, participation in local government is the greatest among groups of people of more than 30 years old. That is, older people participate more in community engagement. Other research demonstrates that people between the ages of 50 and 74 participate in citizen consultation twice as much as younger people (CLG 2009, Brodie et al. 2009).

H4: A community with a large proportion of minority groups has less viable community engagement.

H5: A community with a large female population has less viable community engagement. H6: A community with a large older population has more viable community engagement.

\section{Data and Methodology}

In this analysis, we are interested in the varying degrees of community engagement in Baltimore City (Fig. 2). Accordingly, the dependent variable is the degree of community engagement in each neighborhood (Table 1). Community engagement implies diverse involvement, such as offering opinions, proposing ideas, influencing decision making, and taking responsibility. One of the fundamental factors in community engagement is the voting behavior (Costa and Kahn 2003, Jenkins et al. 2003). The Jacob France Institute (2013) employs the ratio of people who are registered to vote and who voted in the last general elections as a proxy of community engagement. In order to account for community engagement, this study refers to voting behaviors in the community by using both the 'registered to vote' rate and the 'general voter' rate, respectively.

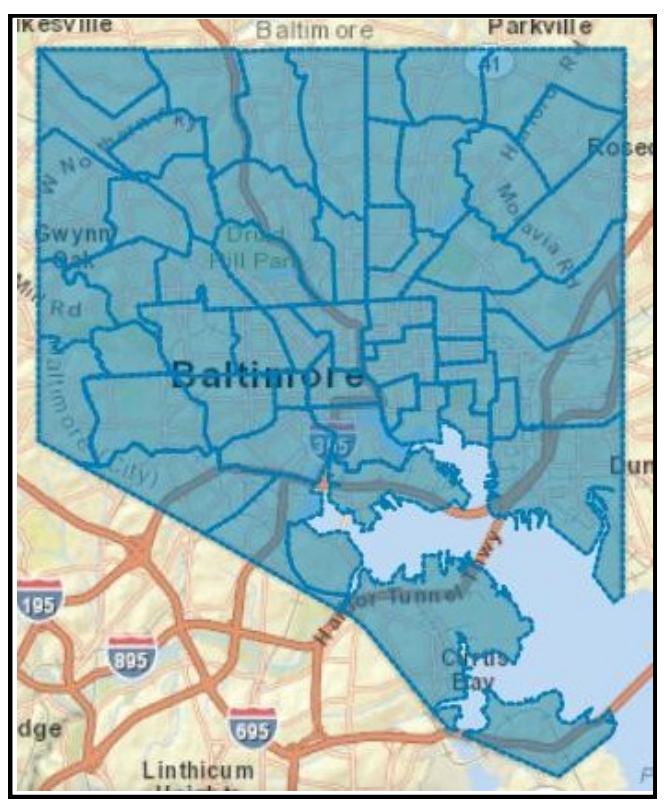

Fig. 2 - Community Map of Baltimore City Source: Jacob France Institute (2013) 
The Degree of Community Engagement: Empirical Research in Baltimore City

\section{Communities in Baltimore City}

\begin{tabular}{|l|l|}
\hline Community Name & \\
\hline Allendale/Irvington/S. Hilton & Howard Park/West Arlington \\
\hline Beechfield/Ten Hills/West Hills & Inner Harbor/Federal Hill \\
\hline Belair-Edison & Lauraville \\
\hline Brooklyn/Curtis Bay/Hawkins Point & Loch Raven \\
\hline Canton & Madison/East End \\
\hline Cedonia/Frankford & Medfield/Hampden/Woodberry/Remington \\
\hline Cherry Hill & Midtown \\
\hline Chinquapin Park/Belvedere & Midway/Coldstream \\
\hline Claremont/Armistead & Morrell Park/Violetville \\
\hline Clifton-Berea & Mount Washington/Coldspring \\
\hline Cross-Country/Cheswolde & North Baltimore/Guilford/Homeland \\
\hline Dickeyville/Franklintown & Northwood \\
\hline Dorchester/Ashburton & Oldtown/Middle East \\
\hline Downtown/Seton Hill & Orangeville/East Highlandtown \\
\hline Edmondson Village & Patterson Park North \& East \\
\hline Fells Point & Penn North/Reservoir Hill \\
\hline Forest Park/Walbrook & Pimlico/Arlington/Hilltop \\
\hline Glen-Fallstaff & Poppleton/The Terraces/Hollins Market \\
\hline Greater Charles Village/Barclay & Sandtown-Winchester/Harlem Park \\
\hline Greater Govans & South Baltimore \\
\hline Greater Mondawmin & Southeastern \\
\hline Greater Roland Park/Poplar Hill & Southern Park Heights \\
\hline Greater Rosemont & Southwest Baltimore \\
\hline Greenmount East & The Waverlies \\
\hline Hamilton & Upton/Druid Heights \\
\hline Harbor East/Little Italy & Washington Village/Pigtown \\
\hline Harford/Echodale & Westport/Mount Winans/Lakeland \\
\hline Highlandtown & \\
\hline
\end{tabular}

To measure community characteristic factors, the study will measure homeownership rates, median income, and percentage of educational levels in the community. For education, we will measure the educational level according to those who have a high school diploma or higher. Finally, to measure the demographic factors, this study includes in its analysis the percentage of African-Americans and Hispanics, the number of people who are 24 to 65 years old and older, and the proportion of the female population. However, due to the high correlation between homeownership and median income, we divide the regression model into two: regression models with homeownership and with median income.

Using the Ordinary Least Squares (OLS) regression, this study will conduct a multiple regression analysis to examine variations in the level of community engagement. In our analysis, two dependent variables - the registered voter rate and the general voter rate - are employed as proxies for community engagement (Table 2 ). 
Variables Specification: Variables, Descriptions, and Data Sources

\begin{tabular}{|l|l|}
\hline \multicolumn{1}{|c|}{ Variable } & \multicolumn{1}{|c|}{ Description and Data Source } \\
\hline Dependent Variable & \multicolumn{2}{|c|}{} \\
\hline Registered voter rate & $\begin{array}{l}\text { Number of residents over the age of 18 who are registered to vote } \\
\text { out of all persons 18 years and older in the community; Source: } \\
\text { Baltimore City Board of Elections }\end{array}$ \\
\hline General voter rate & $\begin{array}{l}\text { Percentage of residents who voted in the last general election out } \\
\text { of all persons 18 years and older in the community; Source: } \\
\text { Baltimore City Board of Elections }\end{array}$ \\
\hline Independent Variable & \multicolumn{2}{|l|}{} \\
\hline African-American & $\begin{array}{l}\text { Percentage of African-American population out of the total } \\
\text { number of residents in each community; Source: U.S. Census } \\
\text { Bureau }\end{array}$ \\
\hline Age 65 and under & $\begin{array}{l}\text { Percentage of Hispanic population out of the total number of } \\
\text { residents in each community; Source: U.S. Census Bureau }\end{array}$ \\
\hline Age over 65 & $\begin{array}{l}\text { Total number of people between 24 and 65 years of age out of all } \\
\text { the people in the community; Source: U.S. Census Bureau }\end{array}$ \\
\hline Female & $\begin{array}{l}\text { Total number of people 65 years of age and above out of all the } \\
\text { people in the community; Source: U.S. Census Bureau }\end{array}$ \\
\hline High school & $\begin{array}{l}\text { Percentage of female population out of the total number of } \\
\text { residents in each community; Source: U.S. Census Bureau }\end{array}$ \\
\hline Hedian income & $\begin{array}{l}\text { Number of people who completed, graduated, or received a high } \\
\text { school diploma divided by the total number of people in the } \\
\text { community; Source: American Community Survey }\end{array}$ \\
\hline College and above & $\begin{array}{l}\text { Number of people who completed, graduated, or received a } \\
\text { college diploma and have also taken some graduate courses } \\
\text { divided by the total number of people in the community; Source: } \\
\text { American Community Survey }\end{array}$ \\
\hline $\begin{array}{l}\text { Total number of households that own their house divided by the } \\
\text { total number of households in each community; Source: American } \\
\text { Community Survey }\end{array}$ \\
$\begin{array}{l}\text { Middle value of the incomes earned by households within a given } \\
\text { area for the prior year (expressed in thousand dollars); Source: } \\
\text { American Community Survey }\end{array}$ \\
\hline
\end{tabular}

The model offered for our analysis measures how community characteristics and demographic factors affect community engagement. The two dependent variables are estimated as shown in the equation:

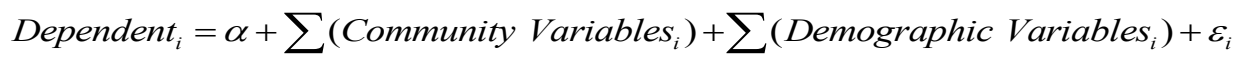

where community characteristics variables consist of one of the two: 1) median income or homeownership rates in the community, and 2) the percentage of people who have a high school level of education or higher in the community. Demographic variables include the ratio of African-Americans and Hispanics out of the total population, the proportion of people who are between the ages of 24 and 65 years old and over, and, finally, the percentage of the female population (Table 3 ). 
The Degree of Community Engagement: Empirical Research in Baltimore City

Table 3

Descriptive Statistics

\begin{tabular}{|l|r|r|r|r|}
\hline \multicolumn{1}{|c|}{ Variable } & \multicolumn{1}{c|}{ Mean } & \multicolumn{1}{c|}{ SD } & \multicolumn{1}{c|}{ Min } & \multicolumn{1}{c|}{ Max } \\
\hline \multicolumn{5}{|c|}{ Dependent Variable } \\
\hline Registered voter rate & 75.82 & 10.92 & 53.20 & 102.59 \\
\hline General voter rate & 52.13 & 10.39 & 28.34 & 81.76 \\
\hline \multicolumn{5}{|c|}{ Independent variable } \\
\hline African-American & 61.79 & 33.32 & 2.67 & 96.70 \\
\hline Hispanic & 4.60 & 6.03 & 0.73 & 30.35 \\
\hline Age 65 and under & 54.62 & 6.59 & 43.55 & 71.48 \\
\hline Age over 65 & 11.72 & 3.65 & 3.80 & 19.20 \\
\hline Female & 53.33 & 2.48 & 47.97 & 59.24 \\
\hline High school & 53.11 & 14.62 & 22.76 & 71.40 \\
\hline College and above & 26.13 & 20.81 & 3.81 & 75.43 \\
\hline Homeownership & 57.93 & 17.36 & 25.60 & 83.60 \\
\hline Median income & 43.42 & 20.01 & 13.48 & 107.67 \\
\hline
\end{tabular}

Results and Discussion

Table 4 provides the regression results for the model, with the registered voter rate as a dependent variable. The model indicates that the ratio of the African-American population has a positive impact on community engagement, while the ratio of the Hispanic population, on the other hand, does not have a significant relationship with community engagement. It provides some evidence that African-American residents participate in their community more than other ethnic groups. In addition, the percentage of people between the ages of 24 and 65 years old and over has a positive impact on community engagement. Specifically, the percentage of people over the age of 65 years old is statistically significant at the level of 5 percent. In terms of the percentage of homeownership, residents who are homeowners are likely to be more engaged in the community, even though it is not statistically significant. Finally, a community with a high median income demonstrates greater participation of the residents in the community, and this finding is statistically significant at the level of 1 percent.

Table 4

\section{Regression Model Result (Dependent Variable: Registered Voter Rate)}

\begin{tabular}{|c|c|c|c|c|c|c|}
\hline Variable & \multicolumn{2}{|c|}{ Coefficient } & Standard Error & \multicolumn{2}{|c|}{ Coefficient } & Standard Error \\
\hline African-American & 0.218 & ** & 0.097 & 0.286 & $* * *$ & 0.077 \\
\hline Hispanic & -0.281 & & 0.297 & -0.289 & & 0.256 \\
\hline Age 65 and under & 0.492 & * & 0.257 & 0.340 & & 0.233 \\
\hline Age over 65 & 0.938 & ${ }^{* *}$ & 0.374 & 0.780 & ** & 0.329 \\
\hline Female & 1.091 & & 0.927 & 1.068 & & 0.729 \\
\hline High school & -0.133 & & 0.382 & -0.359 & & 0.238 \\
\hline College and above & 0.121 & & 0.250 & -0.165 & & 0.188 \\
\hline Homeownership & 0.041 & & 0.138 & & & \\
\hline Median income & & & & 0.336 & *** & 0.100 \\
\hline $\mathrm{R}^{2}$ & \multicolumn{3}{|c|}{0.539} & \multicolumn{3}{|c|}{0.630} \\
\hline
\end{tabular}

Note: ${ }^{* * *},{ }^{* *}$, and ${ }^{*}$ indicate significance at the level of $1 \%, 5 \%$, and $10 \%$, respectively. 
Table 5 delineates the regression results by using different community engagement proxies. The regression model using the general voter rate as a dependent variable reveals similar results with the regression model using the registered voter rate as a dependent variable. The African-American population has a positive impact on community engagement, and this is statistically significant at the 1 percent level. The percentage of people over 65 years of age is also positively related to community engagement. In addition, this regression model finds a significant relationship in the percentage of homeownership in the community, and a high level of homeownership yields a higher degree of community engagement. Median income at the community level also improves the degree of community engagement, and this is statistically significant at the level of 1 percent. Finally, the model doesn't reveal any evidence of a significant relationship between community engagement and the educational level of people in the community.

Regression Model Result (Dependent Variable: General Voter Rate)

Table 5

\begin{tabular}{|c|c|c|c|c|c|c|}
\hline Variable & \multicolumn{2}{|l|}{ Coefficient } & Standard Error & \multicolumn{2}{|c|}{ Coefficient } & Standard Error \\
\hline African-American & 0.262 & *** & 0.078 & 0.265 & $* * *$ & 0.060 \\
\hline Hispanic & -0.306 & & 0.239 & -0.217 & & 0.201 \\
\hline Age under 65 & 0.375 & * & 0.207 & 0.270 & & 0.182 \\
\hline Age over 65 & 0.823 & *** & 0.300 & 0.778 & $* * *$ & 0.258 \\
\hline Female & 0.410 & & 0.745 & 0.929 & & 0.571 \\
\hline High school & -0.228 & & 0.307 & -0.101 & & 0.186 \\
\hline College and above & 0.171 & & 0.201 & 0.964 & & 0.147 \\
\hline Homeownership & 0.209 & * & 0.111 & & & \\
\hline Median income & & & & 0.339 & $* * *$ & 0.078 \\
\hline $\mathrm{R}^{2}$ & \multicolumn{3}{|c|}{0.672} & \multicolumn{3}{|c|}{0.750} \\
\hline
\end{tabular}

Note: ${ }^{* \star *},{ }^{* *}$, and ${ }^{*}$ indicate significance at the level of $1 \%, 5 \%$, and $10 \%$, respectively.

\section{Conclusions}

This research identifies some significant relationships as they relate to what affects community engagement. Both community and demographic factors influence the degree of community engagement. In particular, people with ample financial resources also exhibit a higher level of community engagement. As the extant literature indicates, sufficient financial resources, as evidenced by a high level of median income or a high homeownership rate, may compel citizens to engage more actively in their community. Conversely, the educational level of residents does not have any significant relationship with community engagement in our analysis. This finding indicates that intelligence as a resource makes no difference in community engagement, and, according to the results, educational levels do not play a key role in the participation level of the residents.

These results demonstrate that people with their own house are more willing to participate in community engagement. This is because they are less likely to move to other areas and they attempt to establish durable communities in which to live. Homeowners will contribute more to the community in their activities. This indicates that homeownership is an important factor in community engagement in the neighborhoods. Homeownership compels individuals to form coalitions with one another. In recent years, social capital has been decreasing in much of the country, and homeownership may be one solution to address the issue. 
In addition, people with a high income are more likely to participate in the community. This reveals that financial resources promote citizen engagement in community activities. The necessary financial resources allow citizens more room to invest their time and their money in the community. However, this study has an interesting result related to the race variable. Regarding the demographic factors, African-Americans are more likely to engage in community activities when compared with other ethnic groups, such as the Hispanics. This finding needs to be further investigated in future research.

People over the age of 65 years old also demonstrate a positive relationship with community engagement, but the results reveal that community engagement is not limited to this age group but it rather occurs in a variety of age ranges under and over 65 years old. For future research, a study of the different characteristics based on ethnic groups will be necessary to determine why African-Americans and Hispanics have different results with regard to community engagement, even though they are treated equally as minorities for the purposes of this study. The results from the age groups also require further research to examine disparities more closely. The results imply that material factors are more important in community engagement when compared to racial differences. In urban areas, income level in the community is important in engagement, and African-Americans in the community are also important in engagement. These findings must be compared between rural areas and urban areas.

This study also has some limitations. First of all, it is difficult to identify a direct indicator for community engagement. In our analysis, we used the registered voter rate and the general voter rate as proxies of community engagement, but these proxies may not represent overall community engagement as an indicator. Second, the study used the community of Baltimore City, and Baltimore City has unique characteristics in terms of its poverty rate, racial make-up, and other factors. Thus, it is difficult to generalize the findings to other areas.

However, as mentioned above, there are a few studies on characteristics down to the community level using empirical models. Furthermore, most of the extant research addresses topics related to the effects of community engagement, and most of these studies have been conducted using a qualitative method. Governments have continuously focused on community engagement and its effects on policy adoption and implementation. Even though governments are interested in community-level activities and their impacts, they don't seem to focus much on how to enhance community engagement to improve utilization. This study regarding the influence of community characteristics on community engagement is meaningful in that it may play an important role in creating a bridge to connect government policy makers and the community.

\section{References}

ATTREE P., FRENCH B., MILTON B., POVALL S., WHITEHEAD M., POPAY J. (2011), The experience of community engagement for individuals: a rapid review of evidence, Health \& social care in the community 19 (3), 250-260.

BLAKEY H., PEARCE J. J., CHESTERS G. (2006), Minorities within minorities: Beneath the surface of South Asian participation, Joseph Rowntree Foundation, York, UK.

BLUMENTHAL D. S., DICLEMENTE R. J. (2004), Community-based health research: issues and methods, Springer publishing company, New York.

BOURDIEU P. (1986), The forms of capital, in: Richardson J. (ed.), Handbook of Theory and Research for the Sociology of Education, Greenwood, New York, 241-258.

BRAITHWAITE R. L., BIANCHI C., TAYLOR S. E. (1994), Ethnographic approach to community organization and health empowerment, Health Education \& Behavior 21(3), 407416. 
BRODIE E., COWLING E., NISSEN N., PAINE A. E., JOCHUM V., WARBURTON D. (2009), Understanding participation: A literature review, London: National Council for Voluntary Organizations.

BROWNILL S., DARKE J. (1998), Rich Mix: Inclusive Strategies for Urban Regeneration (Area Regeneration), The Policy Press.

BURTON P., GOODLAD R., CROFT J., ABBOTT J., HASTINGS A., MACDONALD G., SLATER T. (2004), What works in community involvement in area-based initiatives?: a systematic review of the literature, Home Office, London.

CENTERS FOR DISEASE AND PREVENTION (CDC) (1997), Principles of community engagement, CDC/ATSDR Committee on Community Engagement.

COHEN L., BAER N., SATTERWHITE P., WURZBACH M. E. (1994), Developing effective coalitions: an eight step guide, Contra Costa County Health Services Department, Prevention Program.

COLEMAN J. S. (1988), Social capital in the creation of human capital, American Journal of Sociology, S95-S120.

COLEMAN J. S. (1990), Foundations of social theory, Belnkamp, Cambridge MA.

COSTA D. L., KAHN M. E. (2003), Civic engagement and community heterogeneity: An economist's perspective, Perspective on Politics 1 (1), 103-111.

COX K. R. (2011), Commentary. From the New Urban Politics to the 'New' Metropolitan Politics, Urban Studies 48 (12), 2661-2671. Basingstoke.

COXALL B., ROBINS L., LEACH R. (1998), Contemporary British Politics, Macmillan,

FAWCETT S. B., PAINE-ANDREWS A., FRANCISCO V. T., SCHULTZ J. A., RICHTER K. P., LEWIS R. K., LOPEZ C. M. (1995), Using empowerment theory in collaborative partnerships for community health and development, American journal of community psychology 23 (5), 677-697.

HABERIS A., PREDERGAST J. (2007), Councilors Commission Research Report 1: Incentives and Barriers to Becoming and Remaining a Councilor: A Review of the UK Literature, Basingstoke, London.

HANSARD SOCIETY (2009), Audit of Political Engagement 6. The 2009 report: Political Participation and Citizenship, Hansard Society.

HEAD B. W. (2007), Community engagement: participation on whose terms?, Journal of Political Science 42 (3), 441-454.

JACOB FRANCE INSTITUTE (2013), Vital Signs 11. Measuring Progress towards a Better Quality of Life in Every Neghboorhood, Baltimore Neighborhood indicators Alliance, University of Baltimore, Baltimore.

JENKINS K., ZUKIN C., ANDOLINA M. (2003), Three core measures of community-based civic engagement: evidence from the youth civic engagement indicators project, Child Trends Conference on Indicators of Positive Development, March 11-12, Washington, DC.

KEANEY E., ROGERS B. (2006), A Citizen's Duty. Voter Inequality and the Case for Compulsory Turnout, IPPR, London.

KELLOGG FOUNDATION (1997), Sustaining community-based initiatives, Module 1: developing community capacity. An initiative of the W.K. Kellogg Foundation in partnership with the Healthcare Forum, Available online at http://community-wealth.org/_pdfs/tools/cdcs/toolkellogg-cmty-cap.pdf.

LOW N., BUTT S., PAINE E. A., SMITH J. D. (2007), Helping Out: A national survey of volunteering and charitable giving, Cabinet Office, London.

MALOW R. M., ROSENBERG R., JEAN-GILLES M., SAMUELS D., ERGON-PEREZ M. E., JACOBS M. R. (2005), Cultural adaptation in translational research: field experiences, Journal of Urban Health 2 (3), 82-91. 
MCGREGOR A., CLAPHAM D., DONNISON D. (1992), Community participation in areas of urban regeneration, Research Report no. 23, Scottish Homes.

MUSICK M. A., WILSON J. (2007), Volunteers: A social profile, Indiana University Press.

ONYX J., BULLEN P. (2000), Measuring social capital in five communities, The Journal of Applied Behavioral Science 36 (1), 23-42.

PUTNAM R. D., LEONARDI R., NANETTI R. Y. (1993), Making democracy work: civic traditions in modern Italy, Princeton University Press, Princeton, New Jersey.

PUTNAM R. D. (2000), Bowling alone: the collapse and revival of American community, Simon and Schuster, New York.

QUEENSLAND DEPARTMENT OF EMERGENCY SERVICES (2001), Charter for community engagement, community engagement unit, strategic and executive services, Queensland Department of Emergency Services.

RAI S. (2008), Routes and barriers to citizen governance, Joseph Rowntree Foundation. ROHE W. M., VAN ZANDT S., MCCARTHY G. (2002), Home ownership and access to opportunity, Housing Studies 17 (1), 51-61.

SILKA L., CLEGHORN G. D., GRULLON M., TELLEZ T. (2008), Creating community-based participatory research in a diverse community: A case study, J Empir Res Hum Res Ethics 3 (2), 5-16.

STOKOLS D. (1996), Translating social ecological theory into guidelines for community health promotion, American journal of health promotion 10 (4), 282-298.

ZAKOCS R. C., EDWARDS E. M. (2006), What explains community coalition effectiveness?: A review of the literature, American journal of preventive medicine 30 (4), 351 361.

Initial submission: 15.06.2014

Revised submission: 02.12 .2014

Final acceptance: 15.12.2014

Correspondence: Department of Political Science and Public Administration, Mississippi State University, Mississippi State, MS 39762, 404-940-3777, USA

E-mail:sk1315@msstate.edu 
